\title{
Quality of Life of the Patient with Head and Neck Cancer Submitted to Radiotherapy and the Overload of Their Caregivers
}

\author{
Daniela Delalibera $^{1}{ }^{\circledR}$ Alessandra Cristine Ribeiro Carvalho ${ }^{1}$ Bruna Luiza Thesolim ${ }^{1}{ }^{\circledR}$ \\ Laura Ferreira de Rezende ${ }^{10}$
}

${ }^{1}$ Centro Universitário das Faculdades Associadas de Ensino (UNIFAE),

Address for correspondence Daniela Delalibera, Master, Rua Floriano São João da Boa Vista, SP, Brazil Peixoto, 938, SP, Brasil (e-mail: danidelalibera@gmail.com).

Int Arch Otorhinolaryngol 2021;25(4):e536-e544.

\begin{abstract}
Keywords

- head and neck neoplasms

- quality of life

- caregivers

- radiotherapy

Introduction Esthetic and functional changes are frequent in patients with head and neck cancer, and they can be caused by both tumor and treatment. Physical and functional impairment often requires the need of a caregiver, who may feel overwhelmed with the tasks of care.

Objective This study aims to evaluate the quality of life of patients with head and neck cancer submitted to radiotherapy and the overload of their caregivers.

Method This is a quantitative cross-sectional study with 42 patients with head and neck cancer and 17 caregivers evaluated during the radiotherapy treatment. Patients responded to the following questionnaires: Functional Assessment of Cancer Therapy for Head and Neck Cancer (FACT-H\&N) and Shame and Stigma Scale (SSS), while the caregivers responded to the Zarit Burden Interview Scale (ZBI) and Palliative Performance Scale (PPS).

Results Head and neck cancer patients showed a decline in the quality of life in all FACT-H\&N domains, with the domain of additional concerns having the worst outcome. Among the feelings reported by patients, the most important was penitence. Less than half of the patients needed caregivers. It was observed that the greater the degree of commitment of the patient, the greater the degree of overload of the caregiver.

Conclusion Therefore, the quality of life of the patient with head and neck cancer is an important aspect to be considered during the therapeutic choice and in the follow-up of the patient, since it has influenced both the patient and his caregiver.
\end{abstract}

\section{Introduction}

Head and neck cancer (HNC) is the sixth cause of malignant neoplasms in the world and represents a set of tumors that affect the anatomical structures of the oral and nasal cavity, paranasal sinuses, pharynx, larynx, salivary glands and thyroid gland. The most prevalent histological type is squamous cell carcinoma, which accounts for $\sim 90 \%$ of all cases. In Brazil, it is estimated that around 450,000 new cancer cases will occur in 2020 (excluding cases of non-melanoma skin cancer), of which 15,190 will be of the oral cavity, and 7,650 will be laryngeal neoplasms. ${ }^{1-7}$

The treatment of HNC consists of surgery, radiotherapy and chemotherapy or a combination of these approaches. Often, depending on both tumor location/extent and received

November 25, 2019

accepted

August 30, 2020

published online

February 19, 2021
DOI https://doi.org/ 10.1055/s-0040-1718963. ISSN 1809-9777.

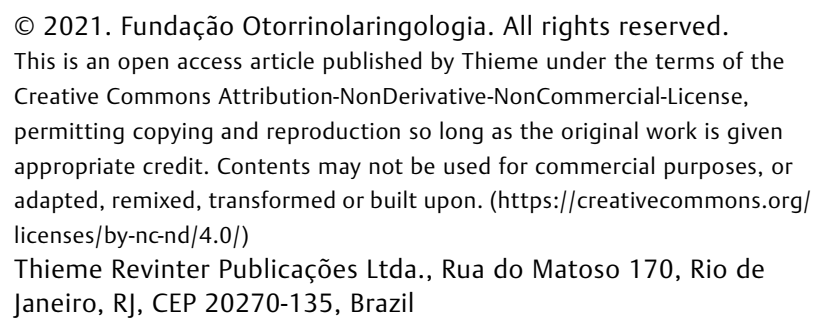


treatments employed, the patient may have local deformities, as well as effects on basic functions such as speaking, breathing, swallowing and eating. These changes can leave patients distressed, with relational difficulties and social isolation, so, all changes resulting from the tumor and treatment can directly impact their quality of life. ${ }^{1,8-12}$

The assessment of the quality of life of patients with head and neck cancer helps in optimizing the therapeutic choice, balancing the patient's needs and gains in the recovery, and, therefore, not based solely on tumor staging and clinical aspects. $^{11,13,14}$

Due to the physical and emotional impairment attributed to cancer, many patients need a caregiver, who is usually a family member. In patients with HNC, the caregiver is usually familybased and assumes various care responsibilities. These activities can have significant consequences and may overwhelm the caregiver. Factors that interfere with the caregiver burden are the time devoted to care, the available financial resources, the caregiver's psychological, physical and social conditions, and the burden derived from caregiving. ${ }^{15-18}$

In this context, the present study aimed to evaluate the quality of life, shame, and stigma of patients with head and neck cancer undergoing radiotherapy as well as caregiver burden.

\section{Method}

\section{Sample}

Quantitative descriptive cross-sectional study conducted at Memorial Radiotherapy Clinic in the city of Poços de Caldas - MG, from April to December 2018. Recruitment occurred as the patient accompanied or not by his caregiver presented to perform the radiotherapy session, both invited to participate in the study. The sample included 42 participants with head and neck cancer and 17 caregivers. The work was approved by the ethics committee Centro Universitário das Faculdades Associadas de Ensino (UNIFAE) by CAAE: 83495118.7 .0000 .5382 .

Inclusion criteria for the patient were: age over 18 years; confirmed diagnosis of head and neck cancer by histopathological examination; being on radiotherapy for cancer. The primary sites included were oral and nasal cavity, paranasal sinuses, pharynx, larynx, glands (parotid, submandibular and sublingual) and hidden primary tumor. For the caregivers, the following inclusion criteria were chosen: age over 18 years, stay with the patient for at least 4 hours a day and for at least 5 days a week, be aware of the patient's disease and be caregiver of the interviewed patient only. The exclusion criterion for both patient and caregiver was the impossibility of answering the questionnaires due to difficulty in understanding the questions.

The patient answered two questionnaires at the same time: Functional Assessment of Cancer Therapy for Patients with Head \& Neck Cancer (FACT-H\&N) -version 4.0 and Shame and Stigma Scale (SSS), translated and validated for Portuguese/Brazil. ${ }^{12,19,20}$

The caregiver answered two questionnaires, the Zarit Burden Interview Scale (ZBI), to assess the caregiver burden, and the Palliative Performance Scale (PPS), to assess the patient's dependence level, both translated and adapted to Portuguese/Brazil. ${ }^{21-23}$

\section{Data Analysis}

For data analysis, we used the JASP version 0.9.0.1 statistical software (Eric-Jan Wagenmakers (room G 0.29) Department of Psychological Methods University of Amsterdam Nieuwe Achtergracht 129B Amsterdam, The Netherlands), with a confidence level of $p \leq 0.05$. In a preliminary way, descriptive measurements of all variables were surveyed, calculating the frequency and percentage of cases for each categorical measure and, for scalar measures, the mean and standard deviation values were obtained.

The Spearman correlation was performed to calculate the associations between the ordinal or scalar variables. Comparisons between two groups were made using the ManWhitney independent sample test. Nonparametric analyses were chosen because the values of the normality test (Shapiro-Wilk) suggested violations

\section{Results}

The study included 42 patients with head and neck cancer during treatment with radiotherapy. The characteristics and clinical data of the patients are described in - Tables $\mathbf{1}$ and $\mathbf{2}$. There was a predominance of males, represented by $78.6 \%$ of the patients, the average age was 60.3 years ( \pm 10.7 ), range 36-79. Of the respondents, $88.1 \%$ were not working at the time of the interview, and the average monthly income of the families was around 2.1 minimum wages ( \pm 1.7 ).

The time elapsed between the 1st symptom and the beginning of treatment was on average 1 year and 4 months $( \pm 1.5)$ with $95 \% \mathrm{CI}(0.9-1.8)$. And the time interval between the $1 \mathrm{st}$ biopsy and treatment was 6 months on average, with $\mathrm{SD}( \pm 8.0)$ and $95 \% \mathrm{CI}(3.6-8.4)$.

The diagnosis was made at a more advanced stage, and $71.4 \%$ of the patients were at stage III or IV at the time of treatment. It was also observed that the worse the staging, the higher the alcohol use and the daily dose $(p<0.05)$. Regarding quality of life, advanced staging showed worse FACT-H\&N response to the additional concern domain $(p<0.05)$.

Of the patients interviewed, $18(42.8 \%)$ had a caregiver, 24 did not need or did not have a caregiver, and only one caregiver refused to participate in the research. The caregivers were mostly female (64.7\%); the average age was 45.6 years ( \pm 14.9 ), with the minimum age being 25 and the maximum age $73 ; 58.8 \%$ were married; and $88.2 \%$ were Catholic, as shown in - Table 3. Regarding family income, the average was $1.9( \pm 1.0)$ minimum wages. Informal caregivers represented $100 \%$ of respondents, with $94.1 \%$ belonging to the family nucleus, and the average daily time devoted to care was 8.0 hours $( \pm 2.5)$.

The FACT-H\&N results are shown in - Table 4 . In the data analysis, when domains were evaluated, the additional concerns (H\&N questions), which presents issues specific to both tumor and treatment symptoms, presented the worst response. Regarding the global scales, the worst was the Trial 
Table 1 Description of patients and caregivers

\begin{tabular}{|c|c|c|c|c|c|}
\hline & \multirow[b]{2}{*}{ Categories } & \multicolumn{2}{|c|}{ Patient $n=42$} & \multicolumn{2}{|c|}{ Caregiver $n=17$} \\
\hline & & Value & \% Total & Value & \% Total \\
\hline \multirow[t]{2}{*}{ Gender } & Female & 9 & 21.4 & 11 & 64.7 \\
\hline & Male & 33 & 78.6 & 6 & 35.3 \\
\hline \multirow[t]{5}{*}{ Marital Status } & Married & 26 & 61.9 & 10 & 58.8 \\
\hline & Divorced & 2 & 4.8 & 2 & 17.7 \\
\hline & Single & 8 & 19.0 & 3 & 5.9 \\
\hline & Stable union & 2 & 4.8 & 2 & 11.8 \\
\hline & Widower & 4 & 9.5 & 0 & 0 \\
\hline \multirow[t]{3}{*}{ Religion } & Catholic & 35 & 83.3 & 15 & 88.2 \\
\hline & Spiritism & 1 & 2.4 & 0 & - \\
\hline & Evangelical & 6 & 14.3 & 2 & 11.8 \\
\hline \multirow[t]{7}{*}{ Educational level } & Illiterate & 4 & 9.5 & 0 & - \\
\hline & Incomplete elementary & 22 & 52.4 & 9 & 52.9 \\
\hline & Complete elementary & 6 & 14.3 & 2 & 11.8 \\
\hline & Incomplete high school & 2 & 4.8 & 1 & 5.9 \\
\hline & Complete high school & 4 & 9.5 & 4 & 23.5 \\
\hline & Incomplete university & 1 & 2.4 & 1 & 5.9 \\
\hline & Complete university & 3 & 7.1 & 0 & - \\
\hline \multirow[t]{12}{*}{ Profession } & Rural activity & 10 & 24.4 & 1 & 5.9 \\
\hline & Cleaning assistant & 2 & 4.7 & 0 & - \\
\hline & Hairdresser & 2 & 4.7 & 0 & - \\
\hline & Merchant & 2 & 4.7 & 1 & 5.9 \\
\hline & Seamstress & 1 & 2.4 & 3 & 17.7 \\
\hline & From home & 1 & 2.4 & 3 & 17.7 \\
\hline & Electrician & 2 & 4.7 & 0 & - \\
\hline & Driver & 4 & 9.7 & 1 & 5.9 \\
\hline & Baker & 2 & 4.7 & 0 & - \\
\hline & Bricklayer & 2 & 4.7 & 0 & - \\
\hline & General services & 3 & 7.3 & 1 & 5.9 \\
\hline & Others & 11 & 26.4 & 7 & 41.3 \\
\hline
\end{tabular}

Table 2 Patient clinical data

\begin{tabular}{|c|c|c|c|c|c|}
\hline Characteristic & Category & Primary subsite & Value & $\%$ & \% Total \\
\hline \multirow[t]{10}{*}{ Cancer type and location } & Oral cavity & & \multicolumn{2}{|l|}{12} & 28.6 \\
\hline & & Lower gum & 2 & 16.6 & 4.8 \\
\hline & & Tongue & 4 & 33.3 & 9.5 \\
\hline & & Retromolar trigone & 4 & 33.3 & 9.5 \\
\hline & & Not localizable & 2 & 16.6 & 4.8 \\
\hline & \multicolumn{2}{|l|}{ Pharynx } & \multicolumn{2}{|l|}{11} & 26.3 \\
\hline & Oropharynx & & 7 & 63.6 & 16.7 \\
\hline & & Amygdala & 5 & 71.4 & 11.9 \\
\hline & & Tongue base & 1 & 14.3 & 2.4 \\
\hline & & Not localizable & 1 & 14.3 & 2.4 \\
\hline
\end{tabular}


Quality of Life of the Patient with Head and Neck Cancer Delalibera et al. 539

Table 2 (Continued)

\begin{tabular}{|c|c|c|c|c|c|}
\hline \multirow[t]{9}{*}{ Characteristic } & Category & Primary subsite & Value & $\%$ & \% Total \\
\hline & \multicolumn{2}{|l|}{ Rhinopharynx } & 2 & 18.2 & 4.8 \\
\hline & Hypopharynx & & 2 & 18.2 & 4.8 \\
\hline & \multicolumn{2}{|l|}{ Salivary glands } & \multicolumn{2}{|l|}{2} & 4.8 \\
\hline & \multicolumn{2}{|l|}{ Larynx } & \multicolumn{2}{|l|}{11} & 26.3 \\
\hline & & Supraglottic & 3 & 27.3 & 7.1 \\
\hline & & Glottis & 8 & 72.7 & 19.0 \\
\hline & \multicolumn{2}{|c|}{ Paranasal sinuses } & \multicolumn{2}{|l|}{1} & 2.4 \\
\hline & \multicolumn{2}{|c|}{ Hidden primary tumor } & \multicolumn{2}{|l|}{5} & 11.9 \\
\hline \multirow[t]{3}{*}{ Histological type } & \multicolumn{2}{|c|}{ Adenoid cystic carcinoma } & \multicolumn{2}{|l|}{1} & 2.4 \\
\hline & \multicolumn{2}{|c|}{ Undifferentiated carcinoma } & \multicolumn{2}{|l|}{3} & 7.1 \\
\hline & \multicolumn{2}{|l|}{ SCC } & \multicolumn{2}{|l|}{38} & 90.5 \\
\hline \multirow[t]{5}{*}{ Staging } & \multicolumn{2}{|l|}{ I } & \multicolumn{2}{|l|}{5} & 11.9 \\
\hline & \multicolumn{2}{|l|}{ II } & \multicolumn{2}{|l|}{5} & 11.9 \\
\hline & \multicolumn{2}{|l|}{ III } & \multicolumn{2}{|l|}{6} & 14.3 \\
\hline & \multicolumn{2}{|l|}{ IV } & \multicolumn{2}{|l|}{24} & 57.1 \\
\hline & \multicolumn{2}{|l|}{ Ignored } & 2 & & 4.8 \\
\hline Treatment & Category & & Value & & \% Total \\
\hline Radiotherapy & Exclusive & & 8 & & 19 \\
\hline & + Chemothera & & 22 & & 52.4 \\
\hline & + Surgery & & 6 & & 14.3 \\
\hline & + Chemothera & urgery & 6 & & 14.3 \\
\hline No. of radiotherapy sessions & Mean (SD) & & 14.1( & & - \\
\hline No. of chemotherapy sessions & Mean (SD) & & $4.0(4$. & & - \\
\hline Habit & Category & & Value & & \% Total \\
\hline Tobacco & Smoking cease & & 29 & & 69.0 \\
\hline & Active smoker & & 6 & & 14.3 \\
\hline & Never smoked & & 7 & & 16.7 \\
\hline Type of cigarette & Industrialized & & 24 & & 68.6 \\
\hline & Handcrafted & & 7 & & 20 \\
\hline & Both & & 4 & & 11.4 \\
\hline Cigarettes a day & Mean (SD) & & 18.51 & & - \\
\hline Consumption time (in years) & Mean (SD) & & 36.6( & & - \\
\hline Alcoholic drink & Stop drinking & & 27 & & 64.2 \\
\hline & Drink & & 1 & & 2.4 \\
\hline & Never drank & & 14 & & 33.4 \\
\hline Type of drink & Distilled drinks & & 22 & & 78.6 \\
\hline & Beer & & 6 & & 21.4 \\
\hline Consumption time (in years) & Mean (SD) & & 31.1 & & \\
\hline
\end{tabular}

Abbreviations: SD, standard deviation; SCC, squamous cell carcinoma. 
Table 3 Descriptive related to care

\begin{tabular}{|l|l|l|l|}
\hline Variable & Category & Value & \% Total \\
\hline Relationship & Wife & 5 & 29.4 \\
\cline { 2 - 4 } & Son/daughter & 6 & 35.3 \\
\cline { 2 - 4 } & Brother/sister & 1 & 5.9 \\
\cline { 2 - 4 } & Husband & 2 & 11.8 \\
\cline { 2 - 4 } & Unrelated & 1 & 5.9 \\
\cline { 2 - 4 } & Nephew/niece & 1 & 5.9 \\
\hline \multirow{4}{*}{$\begin{array}{l}\text { Careful time } \\
\text { of the week) }\end{array}$} & Mean & 6.7 & - \\
\cline { 2 - 4 } & SD & 0.8 & - \\
\hline \multirow{4}{*}{$\begin{array}{l}\text { Account } \\
\text { with help }\end{array}$} & Not & 4 & 23.5 \\
\cline { 2 - 4 } & Sometimes & 6 & 35.3 \\
\cline { 2 - 4 } & Ever & 7 & 41.2 \\
\hline
\end{tabular}

Abbreviation: SD, standard deviation.

Outcome Index (TOI) scale, which is the final total index of the physical and functional domains and additional concerns (H\&N questions).

-Table 5 presents the results obtained in the Shame and Stigma Scale (SSS). Evaluating the subscales, the one with the highest average was the feeling of regret (39.28\%). The subscale that had the lowest impact among respondents was in relation to stigma. Although the issue of stigma and appearance is related to head and neck cancer, the scale had a global average of only $16.55 \%$ ( \pm 16.14$)$.

Patients with caregiver evaluated by the PPS had a mean dependence of $74.12 \%$ ( \pm 15.43 ), and the highest degree of impairment was $50 \%$; the closest to $100 \%$, the lower the impairment. The degree of caregiver burden presented an average of 21.58 ( \pm 12.94 ), and the higher the value, the higher the burden.

The correlations between each domain of the FACT-H\&N questionnaire were positively related, as well as the correlations between each domain of the Shame and Stigma Scale (SSS), the analyzes with statistical significance are shown in - Table 6.
Table 5 Descriptive analysis of the Shame and Stigma Scale (SSS)

\begin{tabular}{|l|l|l|l|}
\hline & Mean \% & SD & CI 95\% \\
\hline Shame with appearance & 12.6 & 19.8 & $(6.7-18.6)$ \\
\hline Sense of stigma & 10.1 & 15.2 & $(5.5-14.7)$ \\
\hline Regret & 39.3 & 33.1 & $(29.3-49.3)$ \\
\hline Speech/social concerns & 17.1 & 24.9 & $(9.5-24.6)$ \\
\hline Total score & 16.5 & 16.1 & $(11.7-21.4)$ \\
\hline
\end{tabular}

Abbreviations: $\mathrm{Cl}$, confidence interval; SD, standard deviation.

The FACT-H\&N instruments and the Shame and Stigma Scale showed a negative correlation between some of their domains. Relevant results are shown in - Table 7.

The Zarit scale, which assessed caregiver burden, was negatively correlated with SPP, Spearman's rho of -0.562 and $p<0.5$, the greater the decline in basic functions, the greater the caregiver burden. Moreover, the fact that the caregiver counted on someone's help revealed a negative correlation with Zarit scale with $p<0.05$.

Quality of life was related to the need for a caregiver, since patients who needed a caregiver had a lower quality of life than patients who did not need care $(p<0.05)$, especially in the domains: physical well-being, social and family wellbeing, functional well-being, and also in relation to the global domains: TOI, Functional Assessment of Cancer Therapy: General (FACT-G), FACT-H\&N, described in - Table 8. When comparing the answers obtained in the FACT-H\&N questionnaire, there was no statistically significant difference between male and female patients. There was also no significance between the answers obtained on the SSS comparing patients with and without caregivers and also between male and female patients.

\section{Discussion}

The patients in this study presented a sociodemographic characterization very similar to that reported in the

Table 4 Descriptive analysis of the Functional Assessment of Cancer Therapy for Head and Neck Cancer questionnaire

\begin{tabular}{|l|l|l|l|l|l|l|}
\hline & Scores & Mean & SD & Median & $\begin{array}{l}\text { Min/ } \\
\max \end{array}$ & $\begin{array}{l}\text { Proportional average to maximum } \\
\text { possible score (\%) (95\% Cl) }\end{array}$ \\
\hline PWB & $0-28$ & 18.7 & 6.2 & 19 & $05-28$ & $66.7(59.9-73.4)$ \\
\hline SWB & $0-28$ & 23.8 & 4.1 & 24.5 & $14-28$ & $84.9(80.4-89.4)$ \\
\hline EWB & $0-24$ & 19.7 & 5.0 & 21.5 & $04-24$ & $82.0(75.8-88.3)$ \\
\hline FWB & $0-28$ & 21.7 & 5.9 & 22.5 & $04-28$ & $77.5(71.1-83.8)$ \\
\hline Additional concerns (H\&N questions) & $0-40$ & 23.1 & 7.8 & 21.5 & $07-40$ & $57.8(51.9-63.7)$ \\
\hline TOI & $0-96$ & 63.6 & 17.0 & 62.5 & $27-95$ & $66.2(60.9-71.5)$ \\
\hline FACT- G & $0-108$ & 83.9 & 17.4 & 87.3 & $31-107$ & $77.7(72.8-82.5)$ \\
\hline FACT-H\&N & $0-148$ & 107.0 & 22.9 & 108.5 & $49-147$ & $72.3(67.6-77.0)$ \\
\hline
\end{tabular}

Abbreviations: Cl, confidence interval; FACT-G, Functional Assessment of Cancer Therapy: General; FACT-H\&N, Functional Assessment of Cancer Therapy for Head and Neck Cancer; EWB, emotional well-being; FWB, functional well-being; PWB, physical well-being; SD, standard deviation; SSS, Shame and Stigma Scale; SWB, social and family well-being; TOI, Trial Outcome Index. 
Table 6 Correlation between domains

\begin{tabular}{|c|c|c|c|}
\hline \multicolumn{4}{|c|}{ Correlation Between FACT-H\&N Domains (Spearman's Rho Positive) } \\
\hline Subscale & FACT-H\&N & & $p$ \\
\hline \multirow[t]{2}{*}{ PWB } & SWB & $* *$ & 0.007 \\
\hline & EWB; FWB; H\&N questions; TOI; FACT-G; FACT-H\&N & $* * *$ & $<0.001$ \\
\hline \multirow[t]{2}{*}{ SWB } & H\&N questions & * & 0.018 \\
\hline & FWB; TOI; FACT-G; FACT-H\&N & ${ }^{* * * *}$ & $<0.001$ \\
\hline \multirow[t]{2}{*}{ EWB } & H\&N questions & * & 0.016 \\
\hline & FWB; TOI; FACT-G; FACT-H\&N & $* * *$ & $<0.001$ \\
\hline FWB & H\&N questions; TOI; FACT-G; FACT-H\&N & **** & $<0.001$ \\
\hline Additional concerns (H\&N questions) & TOI; FACT-G; FACT-H\&N & **** & $<0.001$ \\
\hline TOI & FACT-G; FACT-H\&N & $* * *$ & $<0.001$ \\
\hline FACT-G & FACT- H\&N & $* * *$ & $<0.001$ \\
\hline \multicolumn{4}{|c|}{$\begin{array}{l}\text { Correlation between Shame and Stigma Scale (SSS) domains } \\
\text { (Spearman's Rho positive) }\end{array}$} \\
\hline Subscale & SSS & & $p$ \\
\hline \multirow[t]{2}{*}{ Shame with appearance } & Regret & * & 0.026 \\
\hline & Sense of stigma; regret; total score & $* * *$ & $<0.001$ \\
\hline \multirow[t]{3}{*}{ Sense of stigma } & Regret & ** & 0.003 \\
\hline & Speech/social concerns & ** & 0.002 \\
\hline & Total score & $* * *$ & $<0.001$ \\
\hline Regret & Total score & **** & $<0.001$ \\
\hline Speech/social concerns & Total score & $* * *$ & $<0.001$ \\
\hline
\end{tabular}

Abbreviations: Cl, confidence interval; FACT-G, Functional Assessment of Cancer Therapy: General; FACT-H\&N, Functional Assessment of Cancer Therapy for Head and Neck Cancer; EWB, emotional well-being; FWB, functional well-being; PWB, physical well-being; SD, standard deviation; SSS, Shame and Stigma Scale; SWB, social and family well-being; TOI, Trial Outcome Index.

${ }^{*} p<0.05$

$* 0<0.01$

${ }^{* *} p<0.001$

literature. The most relevant characteristics were the predominance in male patients, the average age around 60 years, low education, low socioeconomic status, and the most prominent profession was rural activity. $3,4,24-26$

The relationship between head and neck cancer and smoking and alcoholism is well documented. Of the interviewed patients, $83.3 \%$ used tobacco and 66.6\% alcohol, which is in agreement with other studies. In addition, patients had prolonged exposure to tobacco and alcohol with a mean of 36.6 years $( \pm 14.78)$ and 31.1 years ( \pm 13.7 ), respectively. These results were similar to those in the study by Santos et al., ${ }^{3}$ who observed approximate results, with an average tobacco use of 30.7 years and alcohol of 31.1 years. ${ }^{4,6,26,27}$

The location of head and neck tumors, in relation to prevalence, varies according to the literature approached. In the present study, oral cavity (28.6\%), pharynx (26.3\%), and larynx (26.3\%) tumors prevailed. $3,4,9,10,17,25,26$ Squamous cell carcinoma was the predominant histological type, which is in agreement to other studies. ${ }^{4,8}$

As for staging, $71.4 \%$ of the patients were in advanced stage (III and IV). Late diagnosis influences therapeutic choice, requiring a more aggressive approach. In addition, the symp- toms are more intense and disabling, contributing to the deterioration of the patient's quality of life, as shown by the FACT-H\&N results. For example, the H\&N questions domain, which is related to tumor symptoms and treatment, presented worse results the more advanced the staging. ${ }^{10,17,24,26}$

Another important factor that interferes with staging, quality of life and prognosis of the disease is the time between symptoms and the beginning of treatment, which in the current study showed a significant delay, with an average of 1 year and 4 months. And although the time between the first biopsy and the start of treatment was less significant, the average time was 6 months. The reasons for the delay between symptoms and the start of treatment may be related to the patient's lack of knowledge about the disease, difficulty in accessing the health system, and slow diagnosis and treatment processes, as described in other studies. $^{28}$

Regarding the therapy used in the interviewed patients, all received radiotherapy, and only 12 (28.6\%) also underwent surgery, which can usually cause aesthetic changes, restriction of independence in daily activities, chewing difficulties, swallowing, speech, disorders of mood and anxiety. Radiotherapy has some advantages over surgery; 
Table 7 Spearman correlations between the Functional Assessment of Cancer Therapy for Head and Neck Cancer domains with the Shame and Stigma Scale domains

\begin{tabular}{|c|c|c|c|}
\hline \multicolumn{4}{|c|}{ Correlation between domains (Spearman's Rho negative) } \\
\hline Subscale & SSS & & $p$ \\
\hline \multirow[t]{4}{*}{ PWB } & Shame with appearance & $*$ & 0.013 \\
\hline & Regret7 & * & 0.036 \\
\hline & Speech/social concerns & **** & $<0.001$ \\
\hline & Total score & *** & 0.002 \\
\hline \multirow[t]{2}{*}{ SWB } & Shame with appearance & ** & 0.007 \\
\hline & Speech/social concerns & ** & 0.004 \\
\hline \multirow[t]{3}{*}{ EWB } & Shame with appearance; regret; total score & *** & $<0.001$ \\
\hline & Sense of stigma & *** & 0.001 \\
\hline & Speech/social concerns & *** & 0.002 \\
\hline \multirow[t]{2}{*}{ FWB } & $\begin{array}{l}\text { Shame with appearance; sense of stigma; } \\
\text { speech/social concerns; total score }\end{array}$ & **** & $<0.001$ \\
\hline & Regret & * & 0.011 \\
\hline $\begin{array}{l}\text { Additional concerns } \\
\text { (H\&N questions) }\end{array}$ & Speech/social concerns & *** & 0.006 \\
\hline \multirow[t]{4}{*}{ TOI } & Shame with appearance & ** & 0.002 \\
\hline & Sense of stigma & $*$ & 0.040 \\
\hline & Regret & * & 0.025 \\
\hline & Speech/social concerns; total score & *** & $<0.001$ \\
\hline \multirow[t]{3}{*}{ FACT-G } & $\begin{array}{l}\text { Shame with appearance; } \\
\text { speech/social concerns; total score }\end{array}$ & **** & $<0.001$ \\
\hline & Sense of stigma & ** & 0.001 \\
\hline & Regret & $*$ & 0.021 \\
\hline \multirow[t]{3}{*}{ FACT-H\&N } & $\begin{array}{l}\text { Shame with appearance; } \\
\text { speech/social concerns; total score }\end{array}$ & $* * *$ & $<0.001$ \\
\hline & Sense of stigma & * & 0.014 \\
\hline & Regret & $*$ & 0.034 \\
\hline
\end{tabular}

Abbreviations: FACT-G, Functional Assessment of Cancer Therapy: General; FACT-H\&N, Functional Assessment of Cancer Therapy for Head and Neck Cancer; EWB, emotional well-being; FWB, functional well-being; PWB, physical well-being; SSS, Shame and Stigma Scale; SWB, social and family wellbeing; TOI, Trial Outcome Index.

${ }^{*} p<0.05$

${ }^{* *} p<0.01$

${ }^{* * *} p<0.001$

however, some patients have undesirable effects, such as oral mucositis, xerostomia, and loss of taste..$^{10,25,29,30}$

The result of the assessment of quality of life in patients with head and neck cancer submitted to radiotherapy through the FACT-H\&N indicates similar points to another study that used the same instrument, but evaluated patients submitted mainly to surgical treatment. According to Nogueira et al. $^{10}$, the domain with the worst result was also the H\&N questions, with a proportional average of 56.0, similar to the present study, which was 57.8. However, there was a divergence regarding the best domain, which was the emotional well-being domain for them and, in this study, it was the social and family well-being domain. Regarding the overall value of FACT-H\&N, in this study, it was higher 107 ( \pm 22.9 ) against 96.6 ( \pm 20.5 ), it cannot be stated that the predominant therapy is the reason for the difference, but it would be interesting to further explore the differences in quality of life between groups of patients exposed exclusively to radiation and surgery.

In another study that monitored the quality of life of head and neck cancer patients throughout radiotherapy treatment, it showed a worsening in the global scales: TOI, FACT-G, and FACT-H\&N. However, two weeks after the end of radiotherapy, there was an improvement in global scales values, showing that undesirable symptoms of radiotherapy such as mucositis and xerostomia generally have a more transient impact on patients' quality of life. ${ }^{30}$

Generally, the disease itself, depending on the therapy employed, especially extensive and mutilating surgery, implies changes in body image and physical appearance, as well as basic functions, such as speaking and swallowing. Consequently, all of these factors often lead the patient to develop negative 
Table 8 Comparison between caregiver and non-caregiver patients regarding the Functional Assessment of Cancer Therapy for Head and Neck Cancer responses

\begin{tabular}{|l|l|l|l|l|l|l|l|}
\hline \multirow{2}{*}{} & \multicolumn{2}{|l|}{$\begin{array}{l}\text { Has no caregiver } \\
\mathbf{n = 2 5}\end{array}$} & \multicolumn{2}{l}{$\begin{array}{l}\text { Has caregiver } \\
\mathbf{n = 1 7}\end{array}$} & W & Rank-Biserial correlation \\
\cline { 2 - 6 } & Mean & SD & Mean & SD & & & \\
\hline PWB & 20.5 & 5.8 & 16.6 & 5.8 & 287.5 & 0.027 & 0.409 \\
\hline SWB & 25.3 & 3.6 & 22.1 & 3.8 & 309.0 & 0.005 & 0.515 \\
\hline EWB & 20.2 & 4.6 & 19.4 & 5.4 & 222.5 & 0.625 & 0.091 \\
\hline FWB & 23.0 & 6.0 & 20.4 & 5.2 & 277.5 & 0.051 & 0.360 \\
\hline H\&N questions & 25.0 & 7.8 & 21.4 & 6.6 & 258.5 & 0.151 & 0.267 \\
\hline TOI & 68.8 & 16.8 & 58.4 & 13.4 & 278.5 & 0.050 & 0.365 \\
\hline FACT-G & 89.1 & 17.8 & 78.7 & 12.9 & 310.5 & 0.005 & 0.522 \\
\hline FACT-H\&N & 114.1 & 22.7 & 100.1 & 17.4 & 293.0 & 0.019 & 0.436 \\
\hline
\end{tabular}

Abbreviations: EWB, emotional well-being; FWB, functional well-being; PWB, physical well-being; FACT-G, Functional Assessment of Cancer Therapy: General; FACT-H\&N, Functional Assessment of Cancer Therapy for Head and Neck Cancer; FWB, functional well-being; SD, standard deviation; SWB, social and family well-being; TOI, Trial Outcome Index; W= comparison test statistic for independent non-parametric Man-Whitney samples. Note: significant $p$-value if less than or equal to 0.05; Rank-Biserial Correlation = effect size.

feelings, such as social isolation, depression, and stigma, which can be defined as a feeling of social disapproval. These feelings were assessed through the SSS instrument, which showed the feeling of regret as the most significant for patients, and stigma as the least important. ${ }^{12,20}$

An important aspect of the results was the evaluation of the item appearance and shame of the SSS, which presented little significant result. Probably, this fact is related to the low rate of surgical intervention among the interviewed patients and, therefore, with less impact on body image.

Feelings related to appearance, shame, stigma, regret, and social isolation explored through the SSS correlated with the patients' quality of life, because global scales, TOI, and FACT-G presented lower values the more important these feelings were for the patient. So, the feelings related to the disease somehow also changed the perception the patients' quality of life. ${ }^{20}$

Similar to other studies, caregivers of head and neck cancer patients are usually women and the patient's spouse, and often have help from another family member. ${ }^{16,17}$ In addition, this research also found that having someone to help with patient care decreases the caregiver burden, with better results on the Zarit scale.

According to Rigoni et al., ${ }^{17}$ caregivers had a compromised quality of life, similar to that of the head and neck cancer patient, showing that not only the patient becomes ill, but also his/her caregiver. The burden suffered by the caregiver plays a relevant role in this aspect, as pointed out by Honório et al., ${ }^{16}$ with the main altered functions in the caregiver's life being overload and routine change.

Generally, there is little concern for the caregiver of the head and neck cancer patient and yet this plays an important role in the patient's quality of life. Through this work, it was noticed that patients with decreased quality of life demanded more from the need to have a caregiver, besides the greater the dependence of the patient the more the caregiver felt burdened.

\section{Conclusion}

The quality of life of patients with head and neck cancer is directly related to the feelings experienced by the patient. In addition, the deterioration in the quality of life usually demands the need for a caregiver. Therefore, it is important to evaluate the interference of treatments on patients' quality of life and feelings, so that the therapeutic decision and follow-up are as optimized as possible for the patient.

Conflict of interests

The authors declare no conflict of interests.

\section{References}

1 Cervenka BP, Rao S, Bewley AF. Head and Neck Cancer and the Elderly Patient. Otolaryngol Clin North Am 2018;51(04): 741-751. Doi: 10.1016/j.otc.2018.03.004

2 Cohen N, Fedewa S, Chen AY. Epidemiology and Demographics of the Head and Neck Cancer Population. Oral Maxillofac Surg Clin North Am 2018;30(04):381-395. Doi: 10.1016/j.coms. 2018.06.001

3 Santos JF, Alves Mda S, Ferreira SMIL, de Sousa NSO, de Oliveira PS. Características dos pacientes com câncer atendidos em um ambulatório de cirurgia de cabeça e pescoço no interior da Bahia. Rev.Saúde. Com 2016;12:528-534

4 de Sousa AR, Koury GVH, Badaranne EBL, Cavalcante Hde A, Araújo CNF. Perfil clínico-epidemiológico de pacientes com câncer de cabeça e pescoço em hospital de referência. Rev Soc Bras Clin Med 2016;14:129-132

5 Instituto Nacional de Câncer José Alencar Gomes da Silva (INCA) Estimativa 2020: incidência de câncer no Brasil. 2019. Rio de Janeiro- RJ. Disponível em: https://www.inca.gov.br/sites/ufu.sti. inca.local/files/media/document/estimativa-2020-incidenciade-cancer-no-brasil.pdf

6 Rettig EM, D'Souza G. Epidemiology of head and neck cancer. Surg Oncol Clin N Am 2015;24(03):379-396. Doi: 10.1016/j.soc.2015. 03.001 
7 Wang T-H, Hsia S-M, Shih Y-H, Shieh T-M. Association of Smoking, Alcohol Use, and Betel Quid Chewing with Epigenetic Aberrations in Cancers. Int J Mol Sci 2017;18(06):1210. Doi: 10.3390/ijms18061210

8 Galbiatti ALS, Padovani-Junior JA, Maníglia JV, Rodrigues CDS, Pavarino ÉC, Goloni-Bertollo EM. Head and neck cancer: causes, prevention and treatment. Rev Bras Otorrinolaringol (Engl Ed) 2013;79(02):239-247. Doi: 10.5935/1808-8694.20130041

9 Rocha BQC, Eneas L, Oliveira RG, Junqueira RB, Verner FS. Características epidemiológicas de pacientes portadores de neoplasias de cabeça e pescoço submetidos à radioterapia em Juiz de Fora - MG. HU Revista 2017;43:71-75

10 Nogueira T-E, Adorno M, Mendonça E, Leles C. Factors associated with the quality of life of subjects with facial disfigurement due to surgical treatment of head and neck cancer. Med Oral Patol Oral Cir Bucal 2018;23(02):e132-e137. Doi: 10.4317/medoral.22072

11 Richardson AE, Morton R, Broadbent E. Caregivers' Illness Perceptions Contribute to Quality of Life in Head and Neck Cancer Patients at Diagnosis. J Psychosoc Oncol 2015;33(04):414-432. Doi: 10.1080/07347332.2015.1046011

12 Pirola WE, Paiva BSR, Barroso EM, Kissane DW, Serrano CVMP, Paiva CE. Translation and cultural adaptation of the Shame and Stigma Scale (SSS) into Portuguese (Brazil) to evaluate patients with head and neck cancer. Rev Bras Otorrinolaringol (Engl Ed) 2017;83(06):697-704. Doi: 10.1016/j.bjorl.2016.10.005

13 Silveira A, Gonçalves J, Sequeira T, et al. [Head and neck cancer: health related quality of life assessment considering clinical and epidemiological perspectives]. Rev Bras Epidemiol 2012;15(01): 38-48. Doi: $10.1590 /$ S1415-790 $\times 2012000100004$

14 Maciel CTV, Leite ICG, Soares TV. Câncer de laringe: um olhar sobre a qualidade de vida. Rev Int Est Exp 2010;2:126-134

15 Ribeiro AF, de Souza CA. O cuidador familiar de doentes com câncer. Arq Ciênc Saúde 2010;17:22-26

16 de Melo Honório I, de Almeida Marques da Cruz FO, Ferreira EB, et al. Ser cuidador de familiar com câncer de cabeça e pescoço. Rev Bras Promoc Saúde 2015;28:337-343. Doi: 10.5020/ 18061230.2015.p337

17 Rigoni L, Bruhn RF, De Cicco R, Kanda JL, Matos LL. Quality of life impairment in patients with head and neck cancer and their caregivers: a comparative study. Rev Bras Otorrinolaringol (Engl Ed) 2016;82(06):680-686. Doi: 10.1016/j.bjorl.2015.12.012

18 de Souza LR, Hanus JS, Dela Libera LB, et al. Sobrecarga no cuidado, estresse e impacto na qualidade de vida de cuidadores domiciliares assistidos na atenção básica. Cad Saude Colet 2015; 23:140-149. Doi: 10.1590/1414-462 × 201500020063
19 Vartanian JG, Carvalho AL, Furia CLB, et al. Questionários para a avaliação de Qualidade de Vida em pacientes com câncer de cabeça e pescoço validados no Brasil. Rev Bras Cir Cabeça Pescoço 2007;36:108-115

20 Kissane DW, Patel SG, Baser RE, et al. Preliminary evaluation of the reliability and validity of the Shame and Stigma Scale in head and neck cancer. Head Neck 2013;35(02):172-183. Doi: 10.1002/hed.22943

21 Scazufca M. Brazilian version of the Burden Interview scale for the assessment of burden of care in carers of people with mental illnesses. Br J Psychiatry 2002;24:12-17. Doi: 10.1590/S151644462002000100006

22 Conselho Regional de Medicina do Estado de São Paulo (CREMESP) Cuidado Paliativo. 2008. São Paulo - SP. Disponível em: http://www.cremesp.org.br/library/modulos/publicacoes/pdf/ livro_cuidado\%20paliativo.pdf

23 Lau F, Downing GM, Lesperance M, Shaw J, Kuziemsky C. Use of Palliative Performance Scale in end-of-life prognostication. J Palliat Med 2006;9(05):1066-1075. Doi: 10.1089/jpm.2006.9.1066

24 Almeida AF, Alves RC, Felix JD, Castro DS, Zandonade E, Rocha RM. Quality of Life in Patients Suffering from Upper Aerodigestive Tract Cancer at a University Hospital. Rev Bras Cancerol 2013;59:229-237

25 Melo Filho MR, Rocha BA, Pires MB, et al. Quality of life of patients with head and neck cancer. Rev Bras Otorrinolaringol (Engl Ed) 2013;79(01):82-88. Doi: 10.5935/1808-8694.20130014

26 Sommerfeld CE, Garcia Andrade M da G, Santiago SM, et al. Qualidade de vida em pacientes com câncer de cabeça e pescoço. Rev bras cir cabeça pescoço 2012;41:172-177

27 Almeida AÁ, Bandeira CM, Gonçalves AJ, Araújo AJ. Nicotine dependence and smoking habits in patients with head and neck cancer. J Bras Pneumol 2014;40(03):286-293. Doi: 10.1590/S1806-37132014000300012

28 Le Campion ACOV, Santos KCB, Carmo ES, et al. Characterization of diagnostic delay in oral and oropharyngeal cancer at two referral centers. Cad Saude Colet 2016;24:178-184. Doi: 10.1590/1414$462 \times 201600020004$

29 de Souza FRN, Barbosa Gde S, Prado Gda M, Schweitzer CM, Júnior EGJ. Qualidade de vida de pacientes submetidos à radioterapia para tratamento de lesões malignas de cabeça e pescoço. Arch Health Invest 2013;2:28-33

30 Franco P, Martini S, Di Muzio J, et al. Prospective assessment of oral mucositis and its impact on quality of life and patientreported outcomes during radiotherapy for head and neck cancer. Med Oncol 2017;34(05):81. Doi: 10.1007/s12032-017-0950-1 